\title{
Peroral endoscopic myotomy and peroral endoscopic pyloromyotomy as a single procedure for concomitant achalasia and gastroparesis
}

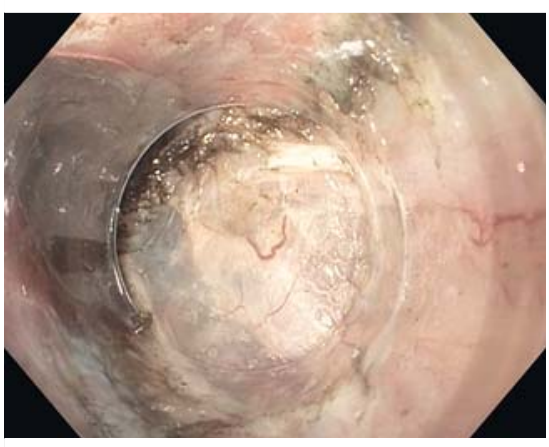

- Fig. 1 Anterior myotomy in the esophagus.

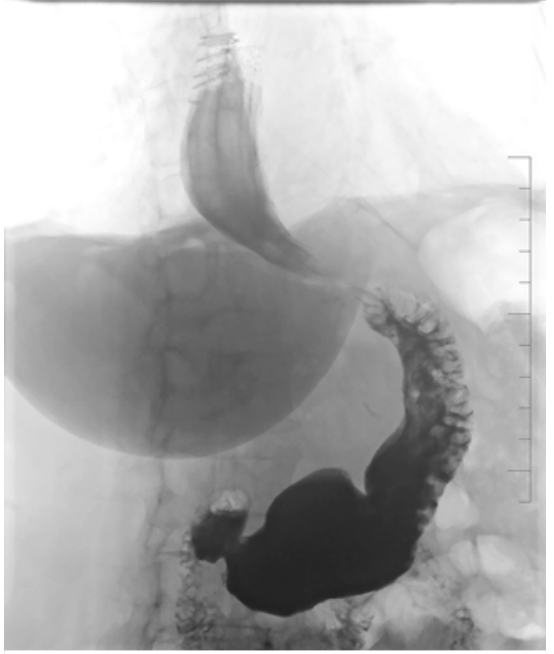

- Fig. $2 \mathrm{X}$-ray on the first postoperative day showed no leakage from either incision, and free passage all the way to the duodenum was evident.

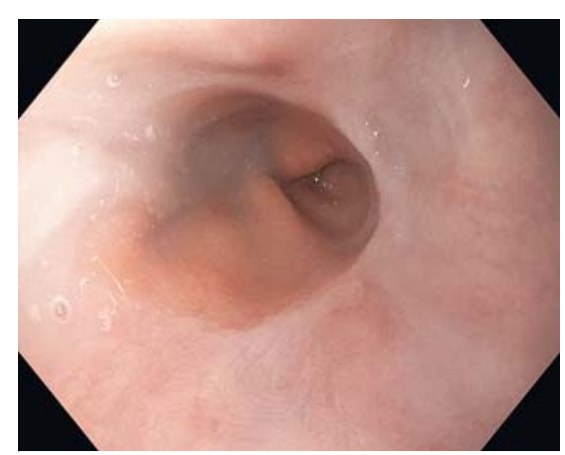

- Fig. 3 Gastrosopy 1 month after the procedure showed a relaxed lower esophageal sphincter.

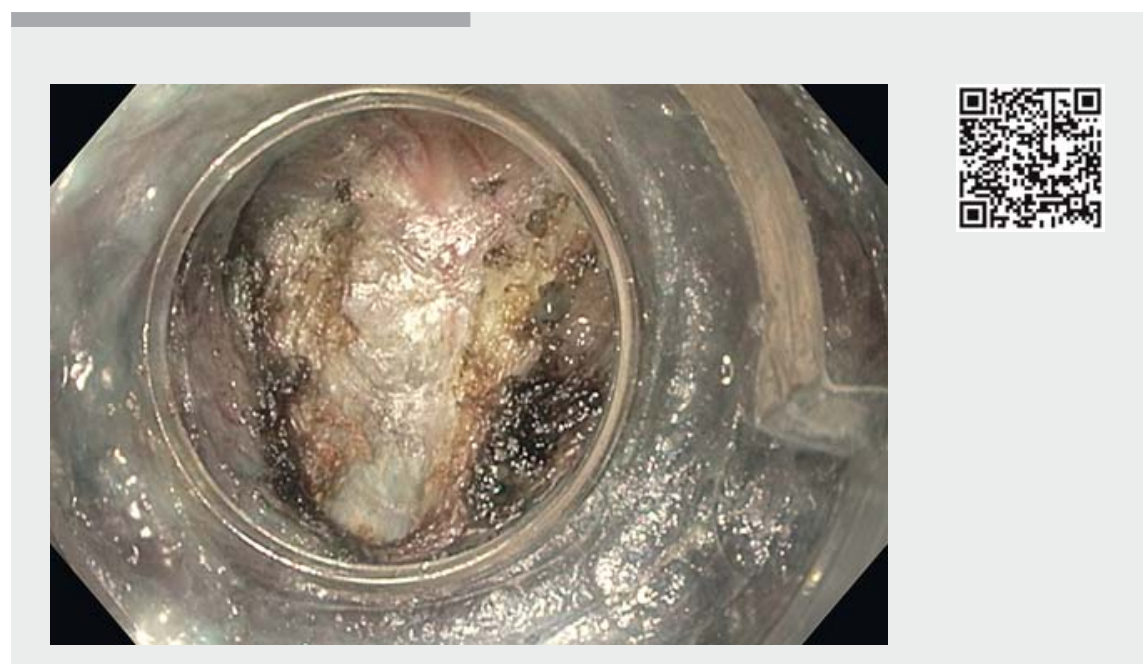

$\checkmark$ Video 1 Peroral endoscopic myotomy and peroral endoscopic pyloromyotomy as a single procedure in a single patient.

Peroral endoscopic myotomy (POEM) has become a standard treatment for achalasia, and peroral endoscopic pyloromyotomy (G-POEM) represents an emerging endoscopic method in the management of refractory gastroparesis. We present a successful procedure combining POEM and G-POEM in one session in a patient with concomitant achalasia and refractory gastroparesis. Although G-POEM and subsequent POEM (after 4 days) have already been performed in one patient [1], a simultaneous myotomy on the lower esophageal sphincter (LES) and the pyloric muscle within a single procedure has not been described.

A 74-year-old woman was referred to our center with achalasia, which was confirmed as type II by high resolution manometry (HRM). She had suffered from long-standing dysphagia and regurgitation, but also complained of vomiting and abdominal fullness. A gastroscopy revealed esophageal stagnation of liquids and spasm of the LES, but also impaired evacuation of the stomach with retained food and spastic pylorus. Delayed gastric emptying was confirmed on the gastric emptying study (GES).
First, we performed an anterior myotomy, $12 \mathrm{~cm}$ in length, in the esophagus ( Fig.1) using a standard tunneling technique with a triangle knife. After completing POEM, we proceeded with a gastric mucosal incision and creation of a short submucosal tunnel along the greater curvature towards the pylorus. Following pyloromyotomy, $3 \mathrm{~cm}$ in length, the incision was closed using endoclips ( $\downarrow$ Video 1 ). The total duration of the procedure was 74 minutes and it was free of adverse events.

On the first postoperative day, an X-ray with water-soluble contrast excluded leakage from both incisions ( $\mathbf{F i g . 2}$ ). The patient was discharged on the third postoperative day and her symptoms had improved tremendously (Eckardt score dropped from 5 to 0 ; Gastroparesis Cardinal Symptom Index from 3.5 to 1 ). HRM, GES, and gastroscopy (\ Fig.3) 1 month after the procedure showed sustained favorable findings, and 1 year after the procedure, the patient had not experienced recurrence of either disease.

Endoscopy_UCTN_Code_TTT_1AO_2AN 
None

The authors

Denisa Erhartova, Zuzana Vackova, Rastislav Hustak, Julius Spicak, Jan Martinek

Department of Hepatogastroenterology, Institute for Clinical and Experimental Medicine,

Prague, Czech Republic

\section{Corresponding author}

\section{Denisa Erhartova, MD}

Department of Hepatogastroenterology, Institute for Clinical and Experimental Medicine, Videnska 1958, Prague 4, Czech Republic

Fax: +420-236-052615

denisaerhartova@gmail.com
[1] Bapaye A, Mahadik M, Pujari R et al. Per-oral endoscopic pyloromyotomy and per-oral endoscopic myotomy for coexisting refractory gastroparesis and recurrent achalasia cardia in a single patient. Gastrointest Endosc 2016; 84: 734-735

\section{Bibliography}

DOI https://doi.org/10.1055/a-0658-5691

Published online: 19.9.2018

Endoscopy 2018; 50: E336-E337

(C) Georg Thieme Verlag KG

Stuttgart · New York

ISSN 0013-726X
ENDOSCOPY E-VIDEOS

https://eref.thieme.de/e-videos

口回 Endoscopy E-Videos is a free Fection, reporting 回舴: on interesting cases and new techniques in gastroenterological endoscopy. All papers include a high quality video and all contributions are freely accessible online.

This section has its own submission website at https://mc.manuscriptcentral.com/e-videos 